\title{
El des-ligaje de la biopolítica para el re-ligaje en la Educación Matemática Decolonial Transcompleja
}

\author{
Milagros Elena Rodríguez
}

\begin{abstract}
Resumen: La manipulación del cuerpo desde la afección de la psique en la enseñanza de la Matemática han sido acciones originarias del ejercicio de autoritarismo de la biopolítica en la educación; el currículo ha sido objeto de dominio de la modernidad-postmodernidad-colonialidad. Desde la hermenéutica comprensiva, ecosófica y diatópica como transmétodo se cumple con el objetivo complejo: des-ligar la biopolítica en la Educación Matemática actual y re-ligar en la Educación Matemática Decolonial Transcompleja. Se pasan por los momentos analíticos, empíricos y propositivos. En este último, se re-liga bajo una concientización tetraédrica: transepistémica, antropoética, política y humana. El re-ligaje es deseable a favor de lo humano, del develar de las Matemáticas del Sur, del habita popular, con un re-ligaje profundo de procesos metacognitivos se puede llegar a una concientización de una Matemática decolonial, compleja, transdisciplinar en la vida del discente; inclusión sin preeminencia, pues la Matemática no tiene más apellido que: la humanidad.
\end{abstract}

Palabras clave: Re-ligaje. Des-ligaje. Biopolítica. Educación Matemática. Decolonial Transcompleja.

\section{The de-linking of biopolitics for the re-linking in Transcomplex Decolonial Mathematical Education}

Abstract: The manipulation of the body from the affection of the psyche in the teaching of Mathematics have been actions originating from the exercise of authoritarianism of biopolitics in education; the curriculum has been the object of the domain of modernity-postmodernitycoloniality. From the comprehensive, ecosophic and diatopic Doctora en Patrimonio Cultural y Doctora en Innovaciones Educativas. Docente de los Postgrados: Educación, Administración y Biología de la Universidad de Oriente (UDO) Núcleo de Sucre: Cumana. Sucre Venezuela. orcid.org/0000-0002-0311-1705 $\bowtie$ melenamate@hotmail.com

Recebido em 06/08/2020 Aceito em 16/10/2020 Publicado em 17/11/2020 hermeneutics as transmethod, the complex objective is fulfilled: to unlink biopolitics in current Mathematics Education and to re-link in Transcomplex Decolonial Mathematical Education. They go through analytical, empirical and purposeful moments. In the latter, it is re-linked under a tetrahedral consciousness: transepistemic, anthropoetic, political and human. The re-linkage is desirable in favor of the human, to unveil the Mathematics of the South, of the popular habitats, with a deep re-linkage of metacognitive processes it is possible to reach an awareness of decolonial, complex, transdisciplinary Mathematics in life of the learner; inclusion without preeminence, since Mathematics has no surname other than: humanity.

Keywords: Re-linking. Detachment. Biopolitics. Mathematics Education. Transcomplex Decolonial.

\section{A desassociação da biopolítica para a revinculação na Educação Matemática Decolonial Transcomplex}

Resumo: A manipulação do corpo a partir do afeto da psique no ensino da Matemática tem sido ações originárias do exercício do autoritarismo da biopolítica na educação; o currículo foi objeto 
do domínio da modernidade-pós-modernidade-colonialidade. A partir da hermenêutica abrangente, ecossófica e diatópica como um transmétodo, o complexo objetivo é cumprido: desvincular a biopolítica na Educação Matemática atual e re-vincular na Educação Matemática Decolonial Transcomplexa. Eles passam por momentos analíticos, empíricos e intencionais. Neste último, é re-ligado sob uma consciência tetraédrica: transepistêmica, antropoética, política e humana. A re-ligação é desejável a favor do humano, para desvendar a Matemática do sul, dos habitats populares, com uma profunda re-ligação de processos metacognitivos, é possível alcançar uma consciência da Matemática decolonial, complexa e transdisciplinar na vida. Do aluno; inclusão sem preeminência, pois a Matemática não tem sobrenome além de: humanidade.

Palavras-chave: Re-ligação. Desvinculando. Biopolítica. Educação Matemática. Transcomplex Decolonial.

\begin{abstract}
Ha habido, en el curso de la edad clásica, todo un descubrimiento del cuerpo como objeto y blanco de poder. Podrian encontrarse fácilmente signos de esta gran atención dedicada entonces al cuerpo, al cuerpo que se manipula, al que se da forma, que se educa, que obedece, que responde, que se vuelve hábil o cuyas fuerzas se multiplican (Foucault, 2003)
\end{abstract}

\title{
1 Rizoma exordio y transmétodo: la hermenéutica comprensiva, ecosófica y diatópica
}

Cuando revisamos las palabras del epígrafe que aluden al tema de investigación con Michel Foucault nos interpelamos: no estamos en la Edad Clásica diría que estamos en la época globalizada tecnológica; pero en sus palabras: ¿hay algún parecido con la realidad: se manipula el cuerpo, se educa para obedecer al sistema predominante; se vuelve hábil a ello el ser humano? Desde mi trinchera complejizada diría que sí, lamentándolo mucho. Y la educación es el medio de poder más efectivo para la dominancia colonial de las mentes, ser y hacer; desde luego con nuevos dispositivos de poder.

En consonancia con lo anterior, la crisis en la Educación Matemática hoy en esta investigación se explicita desde el ejercicio biopolítico en dicho proceso de enseñanza. ¿Qué es la biopolítica? No haremos un listado de la categoría muchas veces heredada del genealogista postcolonialista Michel Foucault, tampoco entraremos en tensiones entre Foucault y Arendt (ILIVITZKY, 2012); sino que iremos a las obras originales a develar la soslayación que ocurre en la Educación Matemática atendiendo también estudios con autores originales, actualmente en la era de la globalización y la emergencia educativa pretendida a resolver con el uso de las redes y los estudios encuarentenados.

Debemos aproximarnos a la respuesta de la pregunta anterior. La biopolítica es "lo que hace entrar a la vida y sus mecanismos en el dominio de los cálculos explícitos y convierte al poder-saber en un agente de transformación de la vida humana" (FOUCAULT, 2008, p. 135). 
Desde luego, este concepto corresponde a los puntos de encuentros y lo tocado entre lo biológico y lo político en la época contemporánea. ¿Estamos diciendo que el cuerpo se afecta con el ejercicio soslayador autoritario de un proyecto de dominancia con la Educación Matemática? Si, desde luego que sí; pues al afectar la psique del ser humano se afecta el cuerpo; considerando que el humano ser es cuerpo-mente-alma y espíritu, desde la complejidad como visión transparadigmática dicha tetra no se desune. Profundizaremos tales afirmaciones prontamente en la indagación.

Nos apresuramos a afirmar que Valero y García (2014) ya reconocen que el currículo de las Matemáticas escolares está inmerso en el gobierno del sujeto moderno; ese sujeto modernopostmoderno-colonial sigue en la misma esquina de la dominación; que se permuta y disfrazada de innovadora y que re-inventa cada día su ejercicio dominante de las mentes, ser y hacer del discente y en general de los actores del proceso educativo; no soslaya quien no está soslayado.

Como investigadora, agente de cambio, sujeto doliente de la crisis e inmersa en el discurso transmetódico que preciso más delante confieso que en estudios actuales de un Postdoctorado en Enseñanza de la Matemática, el matemático que conduce uno de los seminarios impuso un libro único de estudio, cuando se le consultó sobre otros cariados textos a revisar expreso: debo revisarlo para autorizar su uso; es decir que la vieja dominación del texto único al cual deben consultar y sobre el que se deben guiar los estudiantes es decidido e impuesto. Tan acción me recordó mi época de formación de matemático donde esas prácticas opresoras eran normalizadas en los departamentos de las universidades. Desde luego, ya como agente de cambio puedo decidir a quién consultar, la diversidad de fuentes y la liberación del pensamiento que ha pasado por un de-ligaje y que sigue vigilante en dicho proceso. ¿Pero están formados los discentes a niveles básicos de estudios para no ser sometidos y oponerse a ello? ¿Qué sucede en sus cuerpos y como accionan ante la vida en dichos procesos de sometimiento? Son preguntas a responder en esta investigación.

Por otro lado, ¿qué significa re-ligar?, ¿qué condiciones son urgentes para que ello se pueda dar evitando las consecuencias del abuso de la biopolítica?; re-ligar como emergencia en el pensamiento transmoderno es "deconstruir viejos paradigmas cimentados en formaciones tradicionalistas que nos incitan a formarnos desde la reforma del pensamiento, y conformar parte dignamente del grupo de unos pocos ávidos de cambio" (RODRÍGUEZ, 2018, p. 73). Todo ello es posible considerando el otro encubierto al que Dussel (1994) hace mención que fue soterrado 
desde 1492 con toda su esencia de cultura milenaria, y que las consecuencias están vivas hoy bajo un proceso de colonialidad.

Cambiando de ideas, el objetivo complejo de esta investigación es des-ligar la biopolítica en la Educación Matemática actual y re-ligar en la Educación Matemática Decolonial Transcompleja, desde el transmétodo la hermenéutica compresiva, ecosófica y diatópica de Rodríguez (2020a). ¿Por qué los transmétodos? ¿Bajo qué premisas?, ¿Qué significan los rizomas? ¿Cuál es el proceso complejo del transmétodo seleccionado? Vamos a responder.

El rizoma denotación ejemplar de la Biología describe la complejidad de la vida misma. El uso de rizomas en la indagación no es una casualidad, es la profunda transdisciplinariedad que le atribuye concepciones entramadas y conformación de mesetas (RODRÍGUEZ, 2020b); "se trata de una anti-genealogía que rompe con las estructuras estáticas divisorias de presentar las indagaciones en las que las partes se dividen indisolublemente en un ir si un venir" (RODRÍGUEZ, 2019 , p. 4).

Es así como, esta indagación va más allá de las líneas divisorias reiterativas en la tradicionalidad que son impuestas a muchos investigadores en revistas internacionales; en construcciones en las universidades: introducción, metodología, resultados y conclusiones (IMRC), va más allá pero las contiene y las complejiza en un estadio de pensamiento donde concluyendo está introduciendo investigaciones y los resultados no son las perennes verdades que se ha creído la ciencia que ha conseguido e impuesto: como por ejemplo la división irrisoria de las Matemáticas escolares y no escolares.

Mientras que, los transmétodos son esencias de la investigación transcompleja, en especial la hermenéutica comprensiva, ecosófica y diatópica como transmétodo rizomático "como transmétodo sólo es posible en la transcomplejidad bajo el proyecto transmoderno" (RODRÍGUEZ, 2020c, p. 12). La transcomplejidad como categoría y transmetodología entresijo una responsabilidad ética del conocer no reduccionista, e inclusiva, a través del "entendimiento de los múltiples niveles de realidad designa la conjunción de lo simple y disciplinar, lo que atraviesa y trasciende a éstas" (RODRÍGUEZ, 2020c, p. 3).

Es de clarificar que en los transmétodos los sujetos investigadores son participes de la investigación con sus subjetividades y sus experiencias intervienen en la construcción; así es común expresiones en primeras personas narrando hechos de la Educación Matemática, siendo en este caso la investigadora matemático y docente de Matemática; además con estudios en 
decolonialidad que dan preeminencia a su re-intervención en dicha crisis. Ello no sería posible con muchos métodos tradicionales.

La hermenéutica comprensiva, ecosófica y diatópica como transmétodo de construcción teórica, conjugado y complejizado su papel histórico decolonial no es explicar lo exterior, aquello en lo que la experiencia se expresa, sino comprender la interioridad de la que ha nacido lo relativo a las categorías de las indagaciones que hemos venido develando; a todos sus saberes; en este caso la hermenéutica comprensiva le permite a la autora, interpelar los territorios temáticos del conocimiento, la imaginación creadora, la actitud transvisionaria, la irreverencia frente a lo conocido, los modos de interrogar la realidad, la criticidad en el hermeneuta, la libertad de pensamiento, entre otras esencias, como las categorías ecosófica y diatopia que aportan al feliz término del objetivo complejo (RODRÍGUEZ, 2020a).

Pasaremos así, con dicho transmétodo por los pasos de Santos (2003) el analítico, empírico y propositivo. En el primer momento, el analítico se interpretará y teorizará el devenir de la problemática que se estudia, extrayendo las ideas fuerzas de las obras de los diferentes autores de la investigación y categorías intervinientes. El segundo momento: el empírico, estuvo enfocado a interpretar la complejidad de las categorías y el devenir en su modo de concebirse, y en especial de cómo se ha llevado a la práctica. La investigadora realizará énfasis en el pensamiento de varios autores confrontando su pensamiento (RODRÍGUEZ, 2020b).

El tercer momento se encauzó a la prefiguración del objeto de estudio: des-ligar la biopolítica opresora en la Educación Matemática actual y re-ligar en la Educación Matemática Decolonial Transcompleja, para el fortalecimiento de este se desprende de los autores y va a buscar un discurso propio de construcción, donde reconstruye y construye, des-liga y re-liga (RODRÍGUEZ, 2020a).

En lo que sigue se confluyen rizomas consecuentes como los rizomas analíticos empíricos que comenzaron en el presente rizoma y siguen en los rizomas: la crisis que promueve la biopolítica en la Educación Matemática y el des-ligaje de la biopolítica como necesidad transepistémica en la Educación Matemática y los rizomas propositivos que va proponiendo religajes de la Educación Matemática a fin de acercarse a una Educación Matemática decolonial planetaria, compleja y transdisciplinar que denominamos Educación Matemática Decolonial Transcompleja (EMDT), línea de investigación de la autora (RODRÍGUEZ, 2020b) culminando con el rizoma conclusivo como continuación de la línea de investigación. 
Se realiza un gráfico a fin de presenta el presente rizoma en cuanto a su transmétodo y como se configura en la investigación (Figura 1).

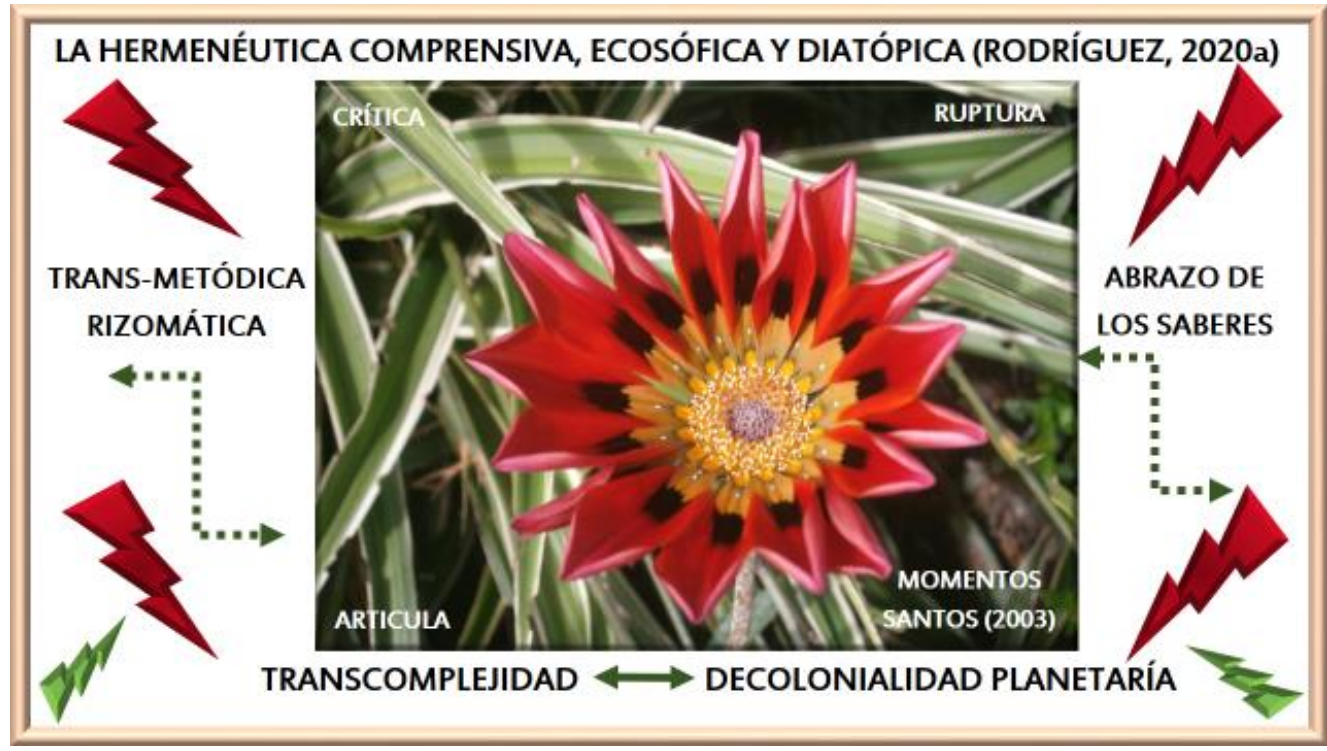

Figura 1: Elaboración de la Autora

2 Rizoma analítico-empírico: la crisis que promueve la biopolítica en la Educación Matemática

Declaramos que hay un proceso de normalización de la educación en general biopolítico y ateniente a intencionalidades de soslayación (VEIGA-NETO, 2013). La Matemática es oprimida en si misma al no ser develada en toda su complejidad en el aula; es una ciencia legado de la humanidad negada en su creación; y en el aula es el fusil que se utiliza para declarar la inoperancia del discente, su incapacidad, su escaza inteligencia, su ineficiencia; la Matemática el pedestal al que pocos pueden acceder; y el docente el ser humano rechazado por apretar el gatillo de ese fusil, que mucha veces no comprende como sus estudiantes con comprendes; y lo pero no es objeto de investigación su práctica educativa.

La educación es una práctica indispensable para la operación biopolítica, lo que representa que la educación irrumpió un lugar estratégico en los procesos en los cuales "el biopoder y los dispositivos de normalización se volvieron dominantes en las sociedades contemporáneas" (VEIGA-NETO, 2013, p. 83). ¿Cómo ha venido imponiéndose esta realidad en la Educación Matemática? El biopoder se ejerce en que el conocimiento se concibe como aquella posesión de la mente del individuo que le admite actuar de "manera poderosa dentro de una sociedad formateada por las Matemáticas" (SKOVSMOSE, 1999, p. 253). Pero cuidado, esa 
manera poderosa no siempre respeta la condición humana; ella ejerce su poder en el cuerpo, en la psique, en las personas, pero las consecuencias en el caso de la Matemática son de dilatado cuidado y de permanente búsqueda de mesetas de salida.

¿Por qué de dilatado cuidado? "la Matemática toca al hombre profundamente y, como la educación, tiene por función revelar el hombre a sí mismo. El que no posee una Educación Matemática se halla privado de algo que es esencial al hombre" (PÉREZ, 1980, p. 42). Estas palabras son de George Papy en una entrevista realizada por Augusto Pérez Lindo en Argentina, donde el matemático belga marco su legado; tal realidad es así ayer y hoy más que nunca; cuando las Matemáticas permean todos los campos del saber; pero en el aula reinan como disciplina intocable que su ejercicio, muchos docentes no quieren indisciplinar la disciplina; es otra arista de la biopolítica a ser desmitificada.

Es de tomar en cuenta que, el ejercicio de la biopolítica también tiene su oportunidad de ejercerse en "las posibilidades variadas y valiosas que las prácticas educativas - escolares y no escolares - nos ofrecen para observar y experimentar el funcionamiento del poder disciplinario, la biopolítica y los dispositivos de normalización y seguridad" (VEIGA-NETO, 2013, p. 83). Aquí la Educación Matemática padece de la separación de las Matemáticas escolares y no escolares, soterrando las mal denominadas no escolares por venir de la cotidianidad, dialogicidad y cultura del discente; la aparta de las escolares que nos las normalizadas e impuesta. Crea un vacío epistemológico como si la Matemática no es una sola ciencia; así como las soterradas Matemáticas del pensamiento del Sur y sólo reconocidas las Matemáticas eurocéntrica imponentes válidas.

Es una variada disposición de dispositivos del poder que utiliza la biopolítica en la Educación Matemática; el hecho de que las Matemáticas son para todos que es legado de la humanidad es un cuenco de mendigo, una falsedad. La legitimación del ser humano deseable y el desadaptado no deseable al sistema; "el hecho de que las Matemáticas escolares fabriquen la idea del niño racional, cosmopolita moderno implica la formación de tesis culturales sobre el tipo de yo que es deseable" (VALERO y GARCÍA, 2014, p. 510); y con ello hay que tener cuidado porque si hay un niño deseado racional conveniente a obedecer al sistema, entonces se separa la posibilidad de abrazo de los seres humanos en su dignidad y condición humana al existir él no deseado; ese que no entra por el filo de la regularización, al que se le atañe su fracaso escolar.

Es así como, normalmente se les alude a que poseen deficiencias en su aprendizaje, 
minimización en su psique y raciocinio; y no es casualidad que pertenezcan a las mal llamadas clases que no son las deseables para el sistema, muchas veces las desfavorecidas por este (VALERO e GARCÍA, 2014); es así como "las explicaciones del fracaso escolar en Matemáticas de ciertos sectores de la población no es, entonces, un caso de deficiencia" (VALERO y GARCÍA, 2014, p. 510). Esta exclusión es impuesta por los poderes de la microfísica del poder.

Desde luego, el poder cuando circula (RODRÍGUEZ, 2014), cuando el discente de Matemática se empodera adecuadamente sin traumas de la Matemática adquiere competencias y mucho más allá de ellas, de una complejidad metacognitiva en su psique para desenvolverse adecuadamente en la vida, para empoderarse de su aprendizaje, emocionado y capaz de compartir con sus compañeros tal hazaña de haber logrado aprehender Matemáticas. Existen ejemplos grandiosos al respecto.

Los hechos de la historia de la Matemática deben ser revisados a fin de llenarnos de sentido matemático vivo; "las Matemáticas nos vinculan con el Ser, con la realidad. En otro sentido, constato que las Matemáticas tocan estructuras psicológicas profundas. (...) la apertura al lenguaje matemático liberaba la personalidad de individuos con desequilibrios mentales" (PÉREZ, 1980. p. 44). Esta realidad es hermosa, y así allí debería dirigirse la biopolítica en la Educación Matemática, a liberar la opresión. Tendremos el momento propositivo del transmétodo que interpela a la investigadora y los autores consultados para ahondar al respecto.

Pero debemos volver al ejercicio antiético que permea la libertad de aprender y de enseñar matemática, "la libertad es la condición ontológica de la ética. Pero la ética es la forma reflexiva que adopta la libertad" (FOUCAULT, 2010, p. 1030). Por ello, si la ética es la antítesis de la condición humana; si es socavado los procesos dialógicos de los niños, sus juegos de como ellos tienen seriedad y experiencias en sus primeros años, entonces se socava su libertad de aprender. Así, el poder en la enseñanza de la Matemática se convierte en autoritarismo y con ellos lleva frustraciones y afecciones en la psique del niño y de la niña, en su cuerpo y en el accionar en su vida.

Los juegos propios de la cotidianidad de los niños y niñas es la seriedad en la que a ellos se le motiva para aprender o develar las nociones de numeración, clasificación, seriación; que en lo concreto ellos ya poseen antes de ir a la escuela; al docente imponerle juegos que no son los de la vida del niño afecta su sentir y su autoestima. Basta con estudiar como un niño aprende y que el proceso abstracción-concreción del aprendizaje ellos lo pueden ascender desde la 
concreción; pues es bien sabido que es la abstracción del niño y de la niña debe esperar a una etapa de maduración. Todo ese tema de conocer de los procesos dialógicos del niño y la niña debe ser un tema central del docente de Matemática.

El docente debe evitar llegar al bloqueo de la psique del niño y la niña

Los niños o individuos que han estado bloqueados para aprender Matemáticas, han estado bloqueados también en su personalidad. Un niño que no aprendió matemáticas se siente disminuido en sí mismo como individuo. Se puede hablar, pues, de una relación profunda entre el conocimiento matemático y la personalidad. Esto no ocurre del mismo modo con otras disciplinas. (PÉREZ, 1980. p. 44).

Nótese el ejercicio de poder en autoritarismo que daña la autoestima del niño; hay me regreso a la sátira de la Matemática como el fusil y el docente rechazado porque aprieta el gatillo. El docente posee en sus variadas innovaciones, la mayoría con tecnologías donde es superado por el discente; pero éste es muy mal guiado en la Matemática y como aprenderla, y es porque el guía, el facilitador que no facilita, el docente, padece de pereza febril (FOUCAULT, 2001) un término para referirse a la repetición memorística incambiable de cómo sólo así se aprende, así de hace y si no se hace pues se mal hace. Esa pereza febril es fragmentaria, repetitiva y discontinua; atentado a la complejidad de la Matemática, de los actores del proceso educativo y de la complejidad que significa educar, y con ello deseable despertar pasión, amor, solidaridad y afectividad por la Matemática.

Se resume el presente rizoma en el gráfico siguiente (Figura 2).

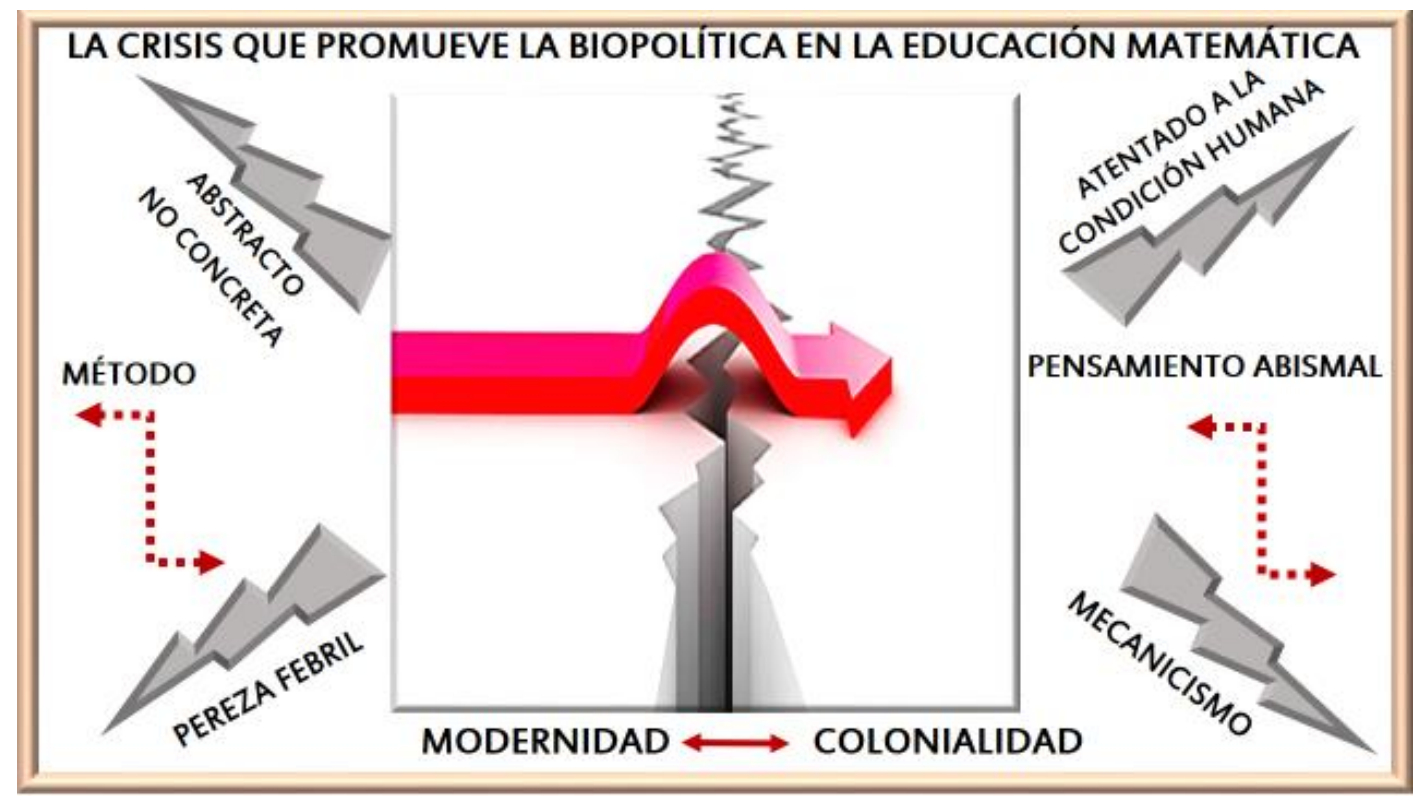

Figura 2: Elaboración de la Autora 


\section{Rizoma analítico-empírico: el des-ligaje de la biopolítica como necesidad transepistémica en la Educación Matemática}

Acá se continua con el momento analítico-empírico del transmétodo la hermenéutica comprensiva; para ello en primera instancia cobra necesidad precisar en la amplitud de lo que significa des-ligar, el des-ligar en este caso. Es importante que esta concepción de des-ligar es urgente a fin de ser incluyente de los soterrados y lo soterrado de la modernidad-postmodernidad; pues es el proceso previo para re-ligar como práctica emergente del pensamiento filosófico transmoderno (RODRÍGUEZ, 2019).

Nótese que el des-ligaje de la biopolítica como necesidad transepistémica en la Educación Matemática, no puede realizarse bajo el mismo pensamiento soterrado que uso la biopolítica como ejercicio de autoritarismo y dominación a la Educación Matemática. Esta esencia es urgente a considerar en las investigaciones; que tal vez dan una de la razones porque lo realizado en la transmodernidad no ha calado los suficiente en algunas ocasiones; es porque las ataduras al viejo pensamiento reduccionista no se han des-ligado suficientemente; esa necesidad de soslayar y ser soslayado no ha querido ser abandonada y los ejercicios de biopoder se reinventan como nuevos dispositivos para disfrazarse de decolonial planetario; como lo ha venido haciendo el pensamiento postmoderno, los ecologistas, entre otros; que al fin son el cono de la modernidad (DUSSEL, 1998).

De igual manera, es urgente considerar que no hay posible decolonialidad si ella no es planetaria; pues caeríamos en los vicios del postcolonialismo; que intenta liberar las mentes soslayadas en Europa si mirar al Sur; de la misma manera no hay una liberación en el Sur sin el Norte: la tierra es una unidad indivisible, así todo lo que en ella habita, así fue creada por Dios. Es así, el momento de considerar que el transparadigma transcomplejo que es complejo y trandisciplinar no puede darse en plenitud bajo las amarras modernistas-postmodernistascoloniales. Ese es un error epistemológico muy común actualmente; que hace razón de porque la educación compleja, por ejemplo, que debe ser transdisciplinar no ha calado suficientemente en las mentes postmodernistas que aún siguen colonizadas. No hay espacios de tiempo para modernidad, postmodernidad y transmodernidad. Son proyectos los dos primeros soslayadores responsables de la inhumanidad del planeta y la transmodernidad un proyecto de liberación de las víctimas de la modernidad-postmodernidad; pero planetaria.

Hemos aclarado tal realidad e insistencias para a fin de convergen en que tampoco se 
puede investigar en la transmodernidad, de la misma manera que el viejo método soslayador de la dominación. Es por ello, que la transmodernidad, transcomplejidad y transmetodología calzan perfectamente en sostén de adherencia e intencionalidad decolonial; de la misma manera que la biopolítica a fin de ejercer un poder que circule y sea ateniente a los procesos dialógicos, sanos, afectivos y respetuosos de la condición humana. Lo que dice que la Educación Matemática debe ser des-ligada de los procesos coloniales del momento.

Preciso, una vez la aclaratoria emergente, que el des-ligar es entonces soltar las amarras de la colonialidad, de la soslayación, es limpiar la psique, llenarse de autoestima; es convivir con los saberes matemáticos del Sur, de las civilizaciones, con la etnomatemática que cobra preminencia; pero des-ligarse también es atender a nuestra condición humana: la toma de conciencia que ha sido más los estudiantes invadidos por la desolación en el aula; por sus proyectos de vida frustrados, y que hace falta buen corazón, dedicación, amor por el ser que espera del docente excelencias; conciencia plena de la infelicidad del ser para cuan águila tomar el vuelo de la metamorfosis de la vieja formación que como docentes nos ha oprimido siendo opresores; esos que el la sátira discursiva decimos que aprieta el gatillo del fusil.

Entonces, para des-ligarse hay que consultar otras fuentes otros ejercicios, mira la necesidad de transdisciplinar, formar grupos colaborativos de aprendizaje; la toma de conciencia de la ética caducada en la Educación Matemática; la historia viva ocultada de la Matemática, las redes de comunicación son fuentes por excelencia para ello; ¿por qué se oculta que lo Mayas son los inventores del cero, y de las diversas formas de representarlos en sus vidas? ¿Por qué la Matemática egipcia tan maravillosa y didáctica para enseñar deviniente de sus procesos de vida, nos es promocionada y conocida en las aulas? ¿Qué ha pasado con nuestro patrimonio matemático, y como reconstruirlo desde el patrimonio histórico de nuestros grupos aborígenes? Si la Matemática devine también de serendipias hermosas que trastocaron a sus creadores para lograr las maravillosas recreaciones de las teorías, ¿Qué serendipias usamos en el aula para que el discente pueda recrearse en la enseñanza?

Si la Matemática está en la naturaleza, en la creación de nuestro cuerpo, en la tierra creación de Dios, ¿por qué la Matemática de la vida de las personas se separan en el aula, se mal denominan no escolares y se alejan en un pensamiento abismal de las escolares, porque intereso y se promovió que esto ocurriera? ¿No ha sido suficientemente deconstruido tal realidad? Todas y más preguntas a responder en el ejercicio antropoético del ser humano docente. Sin opacar para 
nada su ser en su humanidad; por el contrario, mostrarse investigador de su propia práctica, gana respeto y afectividad entre sus discentes, un acercamiento amoroso que se necesita para calar en la vida del otro.

Todas esas esencias son importantes de des-ligar del viejo ejercicio biopolítico para comenzar a volar como el águila con alas y pico nuevo en un re-ligaje de la Educación Matemática (RODRÍGUEZ, 2019). Debemos des-ligar el ejercicio matemático en el aula dejando que esos saberes históricos de lucha (FOUCAULT, 2001), como los soterrados de la Matemática, los cotidianos, los ocultados; los provenientes de la historia y filosofía de la Matemática entren en escena, y dejen la lucha; transversalizándose con los saberes actuales.

Es urgente el des-ligar la posición de sujeto en el docente y objeto en el estudiante que emerge y copia; es con una postura entre humanos ir a un saber ecosófico, como el arte de habitar en el planeta con la con-formación del ciudadano desde los aportes de la Matemática (RODRÍGUEZ, 2013); es así como al des-ligar el poder de soslayación de represión en el aula emergen la consideración de la condición humana, que ha sido motivo de muchos estudios de la autora.

Des-ligar el ejercicio de autoritarismo que significa la imposición de la Matemática abstracta en la vida de los niños y niñas y de divorcio de sus juegos y procesos dialógicos; ello es reafirmar que el niño y niña aprenden de la concreción de sus juegos y que no tiene sentido por ejemplo, comenzar en el nivel inicial imponiéndole al aprendizaje memorístico repetitivo continuo de los números naturales; ellos ya conocen la noción concreta de números y pueden ascender es su diversidad al proceso de seriación. Al fin, el docente decide si encuadra un poder represivo autoritario o un poder que circula y lleva al niño y niña al aprendizaje autónomo y colaborativo.

El des-ligaje de la pereza febril de los docentes al creerse acabado y formado en una Matemática definitiva impuesta en el discente; he hay un asunto delicado; la formación escueta e inconclusa amarrada a la dominación de la biopolítica, debe ser des-ligada en el docente al desligar el pensamiento abismal que impone Occidente en su Matemática modernista - su, porque suyos cree construirla y poseerla —, se aleja a fin de acercar diatópicamente lo separado en un pensamiento recursivo y complejo.

Por otro lado, en las investigaciones sobre Educación Matemática, que son deseables que sean de su propia práctica, deben ir a la liberación ontoepistemológica del ejercicio de sujeto opresor que se ve oprimido al imponer una Matemática divorciada de la historia y filosofía de su 
verdadera creación. Si se sigue investigando de la misma manera opresora se siguen enlistando como militares a obedecer al sistema biopolítico dominante e intencional (RODRÍGUEZ, 2013).

Así mismo, des-ligarse del viejo aparataje que la Educación Matemática se necesaria para tener un profesión y ejercer un oficio únicamente, para converger a la Matemática para la conformación del ser humano (RODRÍGUEZ, 2013); y que para ello "es necesario que la educación logre penetrar en lo más íntimo del ser humano "su conciencia" y que la visión de mundo y universo logren generar una existencia basada en el amor y la libertad del sujeto" (GONZÁLEZ, 2013, p. 167).

En lo que finaliza podemos ejemplificar una vuelta al proceso hermenéutico comprensivo analítico - empírico revisando nuevamente desde interpretaciones de otros autores y así como ahora volver sobre la interpretación y comparatividad con la experiencia de los investigadores. Más aún cuando se trata de biopolítica y diversas aristas que abarca en la Educación Matemática; recomendamos por ejemplo revisar la indagación titulada: La perspectiva de Foucault de los discursos de las clases de Matemáticas: densidad demográfica (TEIXEIRA y GUSMÃO, 2020).

En lo que sigue se presenta un gráfico que pretende resumir el rizoma actual.

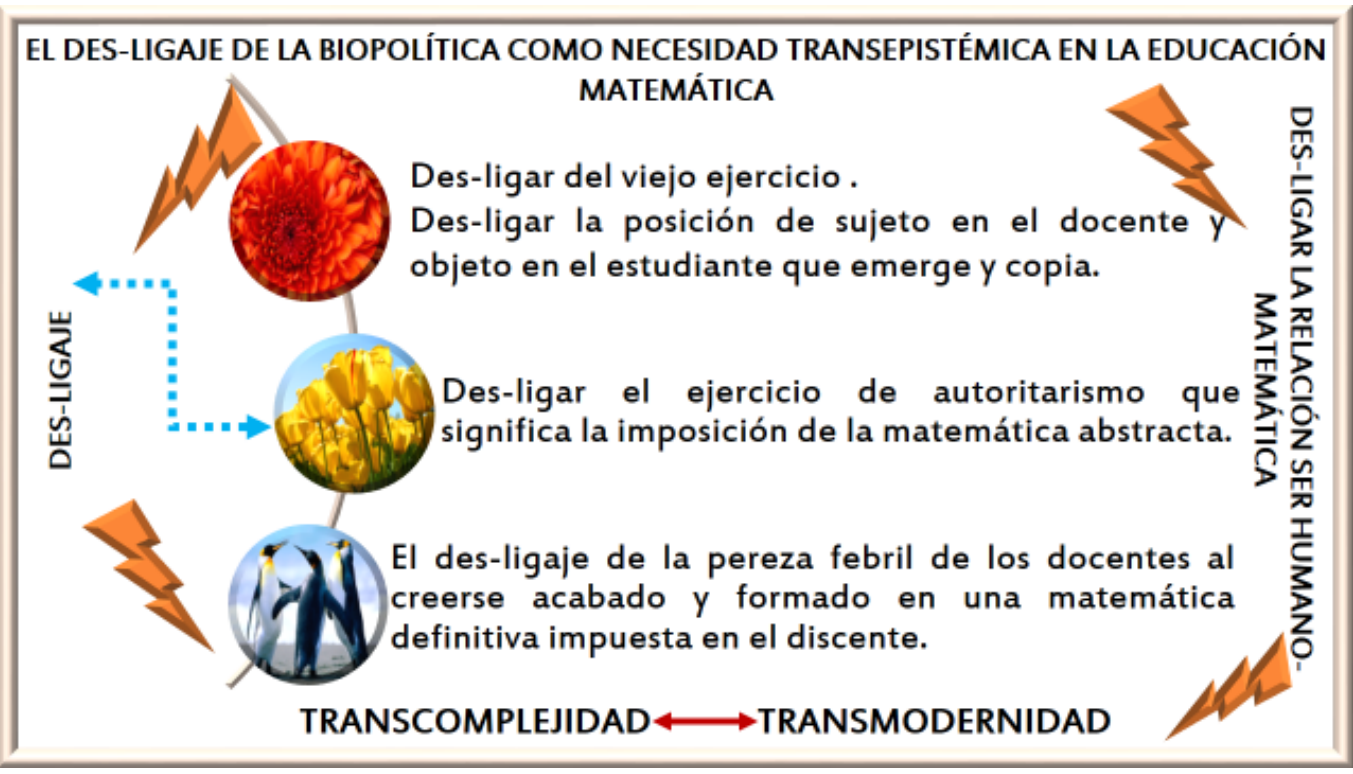

Figura 3: Elaboración de la Autora

4 Rizoma propositivo: el re-ligaje en la Educación Matemática en la Educación Matemática Decolonial Transcompleja

En este momento propositivo del transmétodo hermenéutica comprensiva, seguimos con 
Ios rizomas anteriores; pero nos desprendemos de los autores consultados para ir con un discurso propio de la investigadora que compleja y transdisciplinar en una decolonialidad de la mente intenta ser lo más inclusiva posible; declarando que lo único que excluye es lo que hace excluyente lo que es deseable sea inclusivo en la Educación Matemática.

El re-ligaje lleva una concientización tetraédrica: transepistémica, antropoética, política y humana. Transepistémica porque va más allá de las epistemes tradicionales modernistas. Por ello, ya recorrido la necesidad del des-ligaje de los viejos vicios acomodadizos de la biopolítica en la soslayación de la Educación Matemática vamos, proponiendo re-ligajes de la Educación Matemática a fin de acercarse a una Educación Matemática decolonial planetaria, compleja y transdisciplinar que denominamos Educación Matemática Decolonial Transcompleja, línea de investigación de la autora; como ya se expresó.

En el plano transepistémico; el re-ligaje va a la consideración de ir más allá de lo que se conoce es la Matemática, educar y por ende una forma liberadora de hacer Educación Matemática; esos transepistemes; están cargados de la esencia histórica y filosófica de la Matemática; pero una historia contada con el menor sesgo posible; para ello hay que recorrer a fuentes de las Matemáticas encubiertas como las mayas, aztecas, egipcias; entre otras. El devenir de sus investigadores, su sentir y allí veremos que en ese confluir con las historias del Sur y Occidente nos daremos cuenta de que los puntos de encuentro convergen en una Matemática viva, consustanciada con los procesos dialógicos, llenos y hacedores de la cultura, del avance de las civilizaciones, el desarrollo de las ciencias en general con la convergencia de la Matemática.

De estas realidades, deben estar ávidos los docentes y promover en los discentes tales excelsitudes; educar debe estar cargado de preguntas, de repuestas variadas, de la diversidad de posturas. Además, transcender a educar para la vida, la convivencia el desarrollo de un ser humano verdaderamente humano; donde la condición humana sea respetada en esa conformación del ciudadano; desde luego con competencias y aptitudes; pero no para competir; sino para discernir lo que no conviene, lo antiético, lo disyuntivo y lo excelso de sujeto siendo ser humano. El matemático, docente y todo profesional debe estar formado para la incertidumbre, para la toma de decisiones adecuadas y pertinentes a la tierra-patria.

Para promover la Educación Matemática Decolonial Transcompleja (EMDT) como excelencia y emergencia en el re-ligaje es imperativo saber que es la EMDT, es una práctica para la resistencia decolonial; para la salvaguarda de los saberes matemáticos olvidados y caducados 
a fin de hacerlos abrazar disminuyendo el pensamiento abismal con los que ahora promovemos. Ese plano antropoético, no se desune del transepistémico; pues siempre la Educación Matemática está dirigida a aprender formulas, seguir largos algorítmicos irrespetados en su concreción a favor de la abstracción, mientras que abstracción-concreción no se desune.

Ese plano antropoético debe darle igual importancia al ejemplo, como a la teoría; porque el proceso teoría-ejemplo es un proceso metacognitivo que no se desune; así como lo global-local, ejemplo-contraejemplo, entre otros; como análisis-síntesis, inducción-deducción. Estos procesos que parecen opuestos realmente no están separados; es ahora preciso desde la transdisciplinariedad y complejidad un re-ligar urgente para ir a la metacognición: pensamientos profundos, dejando la pereza febril, va en el ser humano al discernimiento y el abrazo de la coexistencia de lo opuesto, la incorporación del azar, la incertidumbre y la toma de conciencia entre lo conveniente o no. Cuestión que sabemos no ha convenido en la soslayación; bajo esa realidad hay que buscar en esa separación de esos procesos mentales nuevas mesetas en la Educación Matemática.

En el plano político del re-ligaje por supuesto que la Educación Matemática debe ser un ejercicio profundamente político; servidos del otro, liberando las mentes, despertando pasiones por el conocer; despertando la autoestima tantas veces dormida y minimizada en el discente; ese plano político que debe ir a la búsqueda de la verdadera política del poder de la biopolítica a buscar ese poder que dijimos que no siempre es malo, para empoderar al discentes; un poder donde el conocimiento de la Matemática circule con el estudio de otros conocerles, que al fin tienen la Matemática en sí mismos.

Ese plano político ha sido estudiado como antropolitica y lleva sujeto la decolonialidad planetaria; siempre debemos revisar y develar si seguimos bajo los patrones opresores o estamos haciendo Matemática libremente desde todas las formas posibles y no sólo desde las convenientes a las elites; asi deselitizar el proceso biopolítico de la psique y así del cuerpo de los actores del proceso educativo de la Matemática es urgente.

El plano humano en el re-ligaje, ligado a los otros planos, es urgente tomar conciencia que hacer Matemática en el aula es un ejercicio respetuoso de la condición humana y necesario de la convergencia de grupos transdisciplinares; ello no quita la vigilancia epistemológica que siempre se tiene de los conceptos matemáticos. Habrá que re-civilizar nuestro trato como humanos; ese ser que está predispuesto hacia la Matemática tiene historia de vida; ¿Qué les parece si hacemos 
investigación acción participativa compleja con ellos a ver como se empoderan de la necesidad de aprender creyendo que pueden hacerlo?

Re-ligar, es volver a unir lo desunido en la Educación Matemática; que por cierto ha sido la más reduccionista en todo sentido en la educación; volver a disfrutar, reír, gozar en cada acercamiento sabiendo que se puede hacer que se eleva el pensamiento es posible; no debe ser un ejercicio de santuario silencioso en el que nadie interrumpe; donde el docente emite la única posibilidad de hacer y los estudiante copia como un ultimato del proceso. Para remate, así aprendí yo así Ustedes debe hacerlo; entonces en ese re-ligaje se deben responder sobre ¿la educación en la diversidad, con los medios tecnológicos, con los grupos, con las ciencias, con la Educación en la Ciudad profundamente educadora?

Por otro lado, sabemos que tenemos una Educación Matemática, suave en su mecanismo de poder soslayador disfrazada de salidas innovadoras convenientes al poder; podremos bajo el re-ligaje establecer un poder suave continuo a favor de lo humano, del develar de las Matemáticas del Sur, del habitar popular de la ciudad educadora en la que, con un re-ligaje profundo de procesos metacognitivos podamos llegar a una concientización de una Matemática compleja, transdisciplinar desde luego decolonial en la vida del discente; inclusión que significa no excluir, pues la Matemática no tiene más apellido que: la humanidad. El nombre de las Matemáticas eurocéntricas excluyentes son un atentado contra lo declarado por ellos mismos: la Matemática para todos.

En lo que sigue un gráfico que pretende resumir el rizoma.

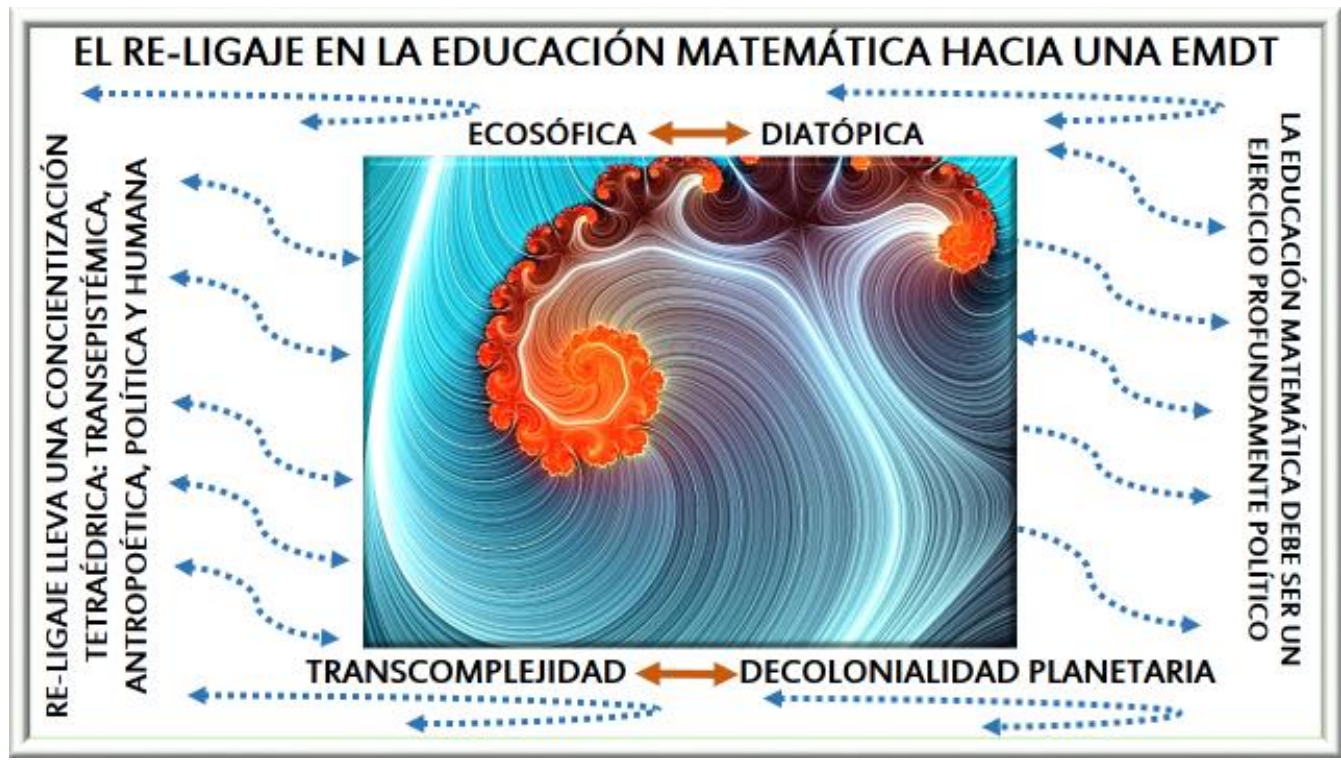

Figura 4 realizada para la investigación 2020 


\section{Rizoma propositivo: culminación de la presente indagación y continuación de la línea} de investigación

Con el uso de los rizomas, más allá de las separabilidades modernistas de las investigaciones en IMRC, se ha cumplido con el objetivo complejo de esta investigación: objetivo complejo: des-ligar la biopolítica en la Educación Matemática actual y re-ligar en la Educación Matemática Decolonial Transcompleja. Todo ello con el transmétodo: la hermenéutica comprensiva ecosófica y diatópica.

La línea de investigación: Educación Matemática Decolonial Transcompleja precisa estudios en pleno ardor como la pereza febril en la Educación Matemática y así muchas otras que en el proyecto decolonial planetario abra su espectro en un inmersionarse en el mar de incertidumbre de la Educación Matemática.

Es de clarificar que la Educación Matemática decolonial lleva cambios muy lentos en algunos países del Sur; lo decolonial planetario no indica radicalidad; ni menos exclusiones. Dejamos claro que el único apellido que lleva la Matemática es HUMANIDAD y así debe ser llevada al aula, sin exclusiones dominios o parcelas; con los aportes que convergen en la esencia compleja de la Matemática que hemos venido atesorando en la indagación.

La decolonialidd no indica que los aportes de algunas civilizaciones respecto a la Matemática serán execrados; por el contrario, se propende sean incluidos convergiendo con el avance de las civilizaciones, la historia y filosofía de la Matemática en su complejo esplendor, el sentir de sus inventores; y el recrearlo en las mentes de los discentes. La compleja relación de la Matemática con todos los saberes de la humanidad; su huella ineluctable; de ello debe estar formado el docente; ese sería un poder que puede circular en la educación y causa bienestar y liberación a las víctimas del proceso soslayador de la Matemática.

Se invita al docente de Matemática a la toma de conciencia de lo que significa educar en la Matemática, a investigar su propia realidad e saber cómo llego a la crisis que ahora atañe al discente, queriendo él mostrarse como él único que puede dominar y conocer Matemática. Es importante, que el docente de Matemática sea un estudioso decolonial, investigador de la vida, de la historia y filosofía que en todo está la Matemática. Es importante que él estudie la forma como se presentan los currículos, y decidir que aplicar en el aula y que no. Es también imperativo que averigüe ahora bajo la luz de la decolonialidad planetaria a ver cómo fue formado; de allí des-ligar para re-ligar en una práctica concientizada continua. 
En el cumplimiento del objetivo complejo, la creación de Dios en cada sentir de su autora, que atiende al amor como su primera excelsitud heredada del Padre Dios amado, me despido dándole las gracias por su infinita sabiduría; en una complicidad especial ocurrida en esta investigación, donde siempre la gloria es de Dios en el nombre de Jesucristo. Así, "Y sobre todas estas cosas vestíos de amor, que es el vínculo perfecto" (Colosenses 3:14), "porque Jehová da la sabiduría, Y de su boca viene el conocimiento y la inteligencia" (Proverbios 2:6).

\section{Referencias}

DUSSEL, Enrique. El encubrimiento del Otro: hacia el origen de mito de la Modernidad. La Paz: Ediciones Plural Editores, 1994.

DUSSEL, Enrique. Ética de la liberación en la edad de la globalización y de la exclusión. Valladolid: Ediciones Trotta, 1998.

FOUCAULT, Michel. Defender la sociedad. Buenos Aires: Fondo de Cultura Económica, 2001.

FOUCAULT, Michel. Historia de la sexualidad. 1. La voluntad de saber. Buenos Aires: Siglo XXI, 2008.

FOUCAULT, Michel. La ética del cuidado de sí como práctica de la libertad. En Estética, Ética, Hermenéutica. Obras esenciales, volumen III. Barcelona: Paidós, 2010.

FOUCAULT, Michel. Vigilar y Castigar. Argentina: Siglo XXI, 2003.

GONZÁLEZ, Juan. Aula mente social. Pensamiento transcomplejo. Tomo III. Barranquilla: Universidad Simón Bolívar, 2013.

ILIVITZKY, Matias. Orígenes de la biopolítica: tensiones entre Foucault y Arendt. Araucaria: Revista Iberoamericana de Filosofía, Política y Humanidades, Sevilla, v. 14, n. 27, p. 24-41, jan./jul. 2012.

PÉREZ, Augusto. Las Matemáticas Modernas: Pedagogía, Antropología y Política. Entrevista a Georges Papy. Perfiles Educativos, Ciudad de México, n. 10, p. 41-46, oct./dic. 1980.

RODRÍGUEZ, Milagros Elena. El poder que se practica, analizado desde Michel Foucault, en la enseñanza de la Matemática. Praxis Educativa ReDIE, v. 5, n. 9, p. 7-24, nov. 2013/abr. 2014.

RODRÍGUEZ, Milagros Elena. La Educación Matemática decolonial transcompleja como antropolítica. Utopía y Praxis Latinoamericana, Zulia, v. 25, p. 125-137, 2020 b.

RODRÍGUEZ, Milagros Elena. La Educación Matemática en la con-formación del ciudadano. Telos: Revista de Estudios Interdisciplinarios en Ciencias Sociales, Zulia, v. 15, n. 2, p. 215-230, may.lago. 2013.

RODRÍGUEZ, Milagros Elena. La educación patrimonial descolonizada: un espacio por construir 
en la transmodernidad. Praxis Educativa ReDIE, v. 10, n. 18, p. 8-32, may./out. 2018.

RODRÍGUEZ, Milagros Elena. La hermenéutica comprensiva, ecosófica y diatópica: un transmétodo rizomático en la transmodernidad. Perspectivas Metodológicas, Buenos Aires, v. 19, p. 1-15, 2020a.

RODRÍGUEZ, Milagros Elena. Matemática-ecosofía: miradas de un acercamiento complejo. Visión Educativa IUNAES, Durango, v.14, n. 29, p. 1-12, abr./sep. 2020c.

RODRÍGUEZ, Milagros Elena. Re-ligar como práctica emergente del pensamiento filosófico transmoderno. Orinoco Pensamiento y Praxis, v. 7, n. 11, p. 13-35, nov./dic. 2019.

SANTOS, Boaventura de Souza. Crítica de la razón indolente: contra el desperdicio de la experiencia. Bilbao: Desclée de Brouwer, 2003.

SKOVSMOSE, Ole. Hacia una Filosofía de la Educación Matemática Crítica. Traducido por Paola Valero. Bogotá: Una Empresa Docente, 1999.

TEIXEIRA, Cymone Martins Cotrim; GUSMÃO, Tânia Cristina Rocha Silva. Perspectiva foucaultiana dos discursos em uma aula de Matemática: densidade demográfica. Educação Matemática Debate, Montes Claros, v. 4, n. 10, p. 1-13, 2020.

VALERO, Pola; GARCÍA, Gloria. El Currículo de las Matemáticas Escolares y el Gobierno del Sujeto Moderno. Bolema, Rio Claro, v. 28, n. 49, p. 491-515, ago. 2014.

VEIGA-NETO, Alfredo. Biopolítica, Normalización y Educación. Pedagogía y Saberes, Bogotá, v. 38, p. 83-91, 2013. 